\title{
CORRESPONDENCE
}

\section{Efomycine M: an inhibitor of selectins?}

\section{To the editor:}

In a recent issue of Nature Medicine, Schön et al. characterized efomycine M (Efo-M) isolated from Streptomyces BS1261 as a specific inhibitor of selectins ${ }^{1}$. The authors showed that Efo-M at low micromolar concentrations is able to block E- and P-selectin interactions with sialyl Lewis ${ }^{\mathrm{x}}$ $\left(s^{\mathrm{x}} \mathrm{x}^{\mathrm{x}}\right.$-bearing ligands, for example, carcinoembryonic antigen (CEA). Moreover, Efo-M inhibited selectin-mediated leukocyte rolling in vivo and substantially improved the clinical symptoms of two in vivo inflammatory skin models using transplanted human skin biopsies. Thus, Efo-M was reported to function as a panselectin antagonist with promising therapeutic potential.

Following the hypothesis by Schön et al., we performed extended in vitro and in vivo investigations with Efo-M. Although in principle we could confirm the anti-inflammatory profile of Efo-M, our findings suggest a mode of action that is separate from pan-selectin inhibition. As shown in Figure 1a, highly purified Efo-M (Supplementary Fig. 1 online) does not compete with the binding of ${ }^{3} \mathrm{H}$-labeled, polyvalent sLe ${ }^{\mathrm{x}}\left({ }^{3} \mathrm{H}-\mathrm{p}-\mathrm{sLe}{ }^{\mathrm{x}}\right)$ to E-, $\mathrm{L}$ - and P-selectins, even at concentrations of $100 \mu \mathrm{M}$ in scintillation proximity assays (SPAs) ${ }^{2}$. In contrast, an excess of unlabeled $\mathrm{p}$-sLe ${ }^{\mathrm{x}}$ as well as fucoidan (Supplementary Fig. 2 online) clearly inhibited the binding of ${ }^{3} \mathrm{H}-\mathrm{p}$-sLe ${ }^{\mathrm{x}}$, whereas monovalent $\mathrm{sLe}^{\mathrm{x}}$ competed with ${ }^{3} \mathrm{H}-\mathrm{p}-\mathrm{Le}^{\mathrm{x}}$ only in binding to E-selectin (Supplementary Fig. 3 online), as described previously ${ }^{3}$. As the experimental setup of SPAs described in Figure 1a allows the quantification of binding only to the glycan binding site of selectins, we repeated the experiment with ${ }^{3} \mathrm{H}$-labeled Efo-M (Fig. 1b), which should allow the detection of Efo-M binding to a glycan-independent binding site. However, no specific (for example, $\mathrm{Ca}^{2+}$-dependent and selectin-specific) binding of ${ }^{3} \mathrm{H}$-labeled Efo-M to L- and P-selectin could be detected. Moreover, measuring direct interactions of Efo-M to selectins in ELISA (Fig. 1c) as well as in highly sensitive Biacore experiments revealed only a weak binding of Efo-M to L-selectin at higher concentrations, and no specific binding of Efo-M to E- and P-selectin in this type of assay was detectable (Fig. 1d).
In their original study and a subsequent publication $^{4}$, Schön et al. showed a model-based alignment of Efo-M and sLe ${ }^{\mathrm{x}}$ structures, suggesting a comparable orientation of hydroxyl groups in Efo-M and sLe ${ }^{\mathrm{x}}$, which are crucial for the adhesive function of selectin ligands. Our analysis using crystallized Efo-M and a liquidstate conformation analysis of Efo-M by nuclear magnetic resonance (NMR) spectroscopy provided no evidence that sLe ${ }^{\mathrm{x}}$ and Efo-M share a three-point pharmacophore when binding to the selectin surface (Supplementary Fig. 4 online). These results as well as the lack of binding of Efo-M to selectins under different experimental conditions suggest an alternative explanation for the findings of Schön et al. Although we observed anti-inflammatory activity in our in vivo models as well (Fig. 1e), Efo-M clearly exhibited selectinindependent effects on immune cells at low micromolar concentrations. Exvivo-stimulated spleen cells from dinitrofluorbenzene-challenged and Efo-M-treated mice produced less tumor necrosis factor (TNF)- $\alpha$ (Fig. 1f). Moreover, in the presence of Efo-M $(10 \mu \mathrm{M})$, activated mouse spleen cells (data not shown) and human peripheral blood mononuclear cells (PBMCs) showed a $50 \%$ reduction in cell viability (Fig. 1g), and lipopolysaccharide (LPS) induced secretion of TNF- $\alpha$ (Supplementary Fig. 5 online). At concentrations of $>10 \mu \mathrm{M}$, Efo-M induced apoptosis in more than $30 \%$ of purified human $\mathrm{B}$ and T cells (Fig. 1h) and inhibited the maturation of dendritic cells (Supplementary Fig. 6 online). Efo-M was cytotoxic in PBMC cultures at low micromolar concentrations (50\% inhibitory concentration $\left.\left(\mathrm{IC}_{50}\right), 4 \mu \mathrm{M}\right)$, indicating again the substantial inhibition of cell viability caused by Efo-M, whereas we observed induction of apoptosis in human endothelial cells with higher concentrations of Efo-M ( $\mathrm{IC}_{50}, 27 \mu \mathrm{M}$; Supplementary Fig. 7 online) and no apoptosis in human neutrophils (data not shown). Together, our findings suggest that a selectinantagonizing function is probably not responsible for the observed in vivo results by Schön et al. and raise questions regarding how Efo-M inhibits inflammatory processes in the skin.

Arne von Bonin ${ }^{1}$, Bernd Buchmann ${ }^{2}$, Ben Bader ${ }^{3}$, Alexandra Rausch ${ }^{1}$, Kristine
Venstrom $^{4,7}$, Martina Schäfer ${ }^{3}$, Stephan Gründemann ${ }^{5}$, Judith Günther ${ }^{5}$, Ludwig Zorn ${ }^{6}$, Reinhard Nubbemeyer ${ }^{6}$, Khusru Asadullah ${ }^{1}$ \& Thomas M Zollner ${ }^{1,7}$

${ }^{1}$ Corporate Research Business Area Inflammation, ${ }^{2}$ Research Center Europe, Med. Chemistry $5,{ }^{3}$ Research Center Europe, Enabling Technologies, ${ }^{4}$ Research Business Area Dermatology USA, ${ }^{5}$ Research Center Europe, Computational Design and Compound Characterization, ${ }^{6}$ Research Center Europe, Microbiological Chemistry, Schering AG, Müllerstr. 178, 13342 Berlin, Germany. ${ }^{7}$ Berlex Biosciences, 2600 Hilltop Drive, Richmond, California 94804, USA. e-mail:arne_von.bonin@schering.de

Note: Supplementary information is available at the Nature Medicine website.

1. Schön, M.P. et al. Nat. Med. 8, 366-372 (2002)

2. Game, S.M. et al. Anal. Biochem. 258, 127-135 (1998).

3. Weitz-Schmidt, G., Gong, K.W. \& Wong, C.H. Anal. Biochem. 273, 81-88 (1999).

4. Wienrich, B.G. et al. J. Invest. Dermatol. 126, 882889 (2006)

\section{Schön et al. reply:}

The hypothesis raised by von Bonin et al. is an interesting extension of our previous findings. However, the single previously known hydrogen bond within the efomycine molecule does not exclude the pharmacophore hypothesis, and the use of artificial selectin molecules for in vitro binding studies needs to be evaluated further. Our own recent report proposes a substantially refined model of efomycine $\mathrm{M}$ binding ${ }^{1,2}$. Although apparently not taken into consideration by von Bonin et al., these results predict a different orientation and stronger binding of efomycine $\mathrm{M}$ (Efo-M) within the binding pocket of E-selectin as compared to $\mathrm{sLe}^{\mathrm{X}}$, a weak binder ${ }^{3}$, thus providing a potential explanation for the observation that Efo-M binding could not be competitively inhibited by $s L e^{\mathrm{X}}$.

Extending previously published functions ${ }^{4}$, the body of evidence that indicates specific interference of Efo-M with selectin-mediated adhesive functions in various in vitro and in vivo experimental settings is growing. This can be illustrated by the following example. 
Upon stable transfection with L-selectin, an L-selectin-negative leukocyte line acquired the capacity to roll on and adhere to immobilized polyvalent sLe ${ }^{\mathrm{X}}$. This clearly L-selectindependent interaction was completely abrogated likewise by Efo-M or an L-selectin-directed antibody $^{5}$. In Biacore experiments, Efo-M showed significant $(P=0.0003$ at $20 \mu \mathrm{M})$ inhibition of L-selectin-dependent adhesion to $\mathrm{sLe}^{\mathrm{X}}$ (ref. 5). The activation of $\mathrm{T}$ cells was not altered by Efo-M, and cytotoxicity even at higher concentrations could not be confirmed independently in three laboratories ${ }^{5}$.

Until a crystal structure of the ligand binding site together with efomycine is available, the exact mode of interaction with selectins will remain somewhat speculative. Although the exact in vivo mode of action of Efo-M remains unclear, there is increasing evidence for interference with selectinmediated functions.

\section{B Gregor Wienrich ${ }^{1,2}$, Gertie J Oostingh ${ }^{1,2}$, RalfJ Ludwig ${ }^{3}$, Sven Enders ${ }^{4}$, Gesche Harms ${ }^{4}$, Rudolf Tauber ${ }^{4}$, Thomas Krahn ${ }^{5}$, Bernd Kramer ${ }^{6}$, W.-Henning Boehncke ${ }^{3}$ \& Michael P Schön ${ }^{1,2}$}

\section{${ }^{1}$ Rudolf Virchow Center, DFG Research Center for Experimental Biomedicine, and ${ }^{2}$ Department of Dermatology, Venereology} and Allergology, University of Würzburg,
Versbacher Str. 9, 97078 Würzburg, Germany. ${ }^{3}$ Department of Dermatology and Venereology, University of Frankfurt, Germany. ${ }^{4}$ Institute for Clinical Chemistry and Pathobiochemistry, Charite University Medical Center, Berlin, Germany. ${ }^{5}$ BayerHealth Care, Wuppertal, Germany. ${ }^{6} 4 S C$ AG, Martinsried, Germany. e-mail:michael.schoen@virchow. uni-wuerzburg.de.

1. Seifert, M.H.J., Schmitt, F., Herz, T. \& Kramer, B. J. Mol. Model 10, 342-357 (2004).

2. Wienrich, B.G., et al. J. Invest. Dermatol. 126, 882889 (2006)

3. Kaila, N. \& Thomas, B.E. Med. Res. Rev. 22, 566-601 (2002).

4. Schön, M.P. et al. Nat. Med. 8, 366-372 (2002).

5. Oostingh, G.J. et al. J. Invest. Dermatol. (doi: 10.1038/ sj.jid.5700504).

Figure 1 No specific Efomycine $\mathrm{M}$ binding to $\mathrm{E}-, \mathrm{L}-$ and $\mathrm{P}$ selectins. (a) Binding of ${ }^{3} \mathrm{H}-\mathrm{p}-\mathrm{sLe} \mathrm{e}^{\mathrm{x}}$ (glycoconjugates ( $p-s \mathrm{Le}^{\mathrm{x}}$, poly[N-(2-hydroxyethyl)acrylamide] with $20 \%$ molar ratio sLe ${ }^{\mathrm{X}}$ ) to selectin fusion proteins was tested in a bead-based scintillation proximity assay (SPA) format similar to one previously described ${ }^{2}$ Protein-A coated SPA-beads $(1 \mu \mathrm{g} / \mu \mathrm{l})$, E-, L- or P-selectin fusion proteins (each $0.5 \mathrm{ng} / \mu \mathrm{l})$ and test compounds $(10 \mu \mathrm{M}$ unlabeled $\mathrm{p}-\mathrm{sL} \mathrm{e}^{\mathrm{x}}$ or Efo-M at the indicated concentrations) were mixed in a 96-well microplate. ${ }^{3} \mathrm{H}-\mathrm{p}$-sLe ${ }^{\mathrm{X}}(1 \mathrm{nCi} / \mu \mathrm{l})$ was added, the microplate was sealed and scintillation was measured after 30 min incubation in a Topcount instrument. Final buffer conditions were $25 \mathrm{mM}$ HEPES, pH 7.4, $137 \mathrm{mM} \mathrm{NaCl}, 2.7 \mathrm{mM} \mathrm{KCl}, 0.5$ $\mathrm{mM} \mathrm{CaCl}_{2}$ and $0.1 \%$ bovine serum albumin. All assay steps were performed at $20^{\circ} \mathrm{C}$ in a total volume of $100 \mu$ l. Addition of EDTA $(10 \mathrm{mM})$ abolished binding of ${ }^{3} \mathrm{H}-\mathrm{p}-\mathrm{sL} \mathrm{e}^{\mathrm{X}}$ to immobilized selectins. Data are mean \pm s.d. from triplicate values.

(b) ${ }^{3} \mathrm{H}-\mathrm{Efo}-\mathrm{M}$ was coincubated with selectin fusion proteins or a control immunoglobulin in a SPA as described in a. (c) Binding to P-Sel-lg was monitored in a cell-free ELISA with horseradish peroxidase-conjugated Streptavidin. Plastic-bound anti-human Ig $(0.5 \mu \mathrm{g} / \mathrm{ml})$ was incubated with P-selectin-lg fusion proteins $(1 \mu \mathrm{g} / \mathrm{ml})$ and binding of biotinylated $\mathrm{p}-\mathrm{sL} \mathrm{e}^{\mathrm{X}}$ was determined. Two different batches of highly purified Efo-M (Charge A, Charge B) did not inhibit this interaction, whereas fucoidan (starting with $200 \mu \mathrm{g} / \mathrm{ml}, 1: 3$ dilutions) or unlabeled p-sLe ${ }^{\mathrm{X}}$ (data not shown) reduced the binding to background levels at higher concentrations. (d) Binding of E-, P- and L-selectin-Ig fusion proteins immobilized on Protein-A beads to chip surface-bound $\mathrm{p}-\mathrm{SLe}^{\mathrm{X}}$ was determined in the absence and in the presence of titrated amounts of Efo$\mathrm{M}$ in BiaCore analysis. (e) Inhibition of contact hypersensitivity following prolonged exposure to Efo-M. Experiments were carried out in accordance with the German Tierschutzgesetz (Animal Protection law) along the guidelines of the Landesamt für Arbeitsschutz, Gesundheit und technische Sicherheit (LAGetSI) of the Land Berlin, Germany. Female NMRI mice (24-28 g) were sensitized and challenged with DNFB according to standard methods. Twenty-four hours before challenge, mice received intraperitoneal injections of Efo-M $(5.0 \mathrm{mg} / \mathrm{kg}$ body weight per dose in DMSO/ethanol/transcutol). Twenty-four hours after DNFB challenge, ear thickness (e) was determined and mice were killed for measurement of neutrophil and granulocyte infiltration (Supplmentary Fig. 8). Data show mean \pm s.d. $n=10$ per group.
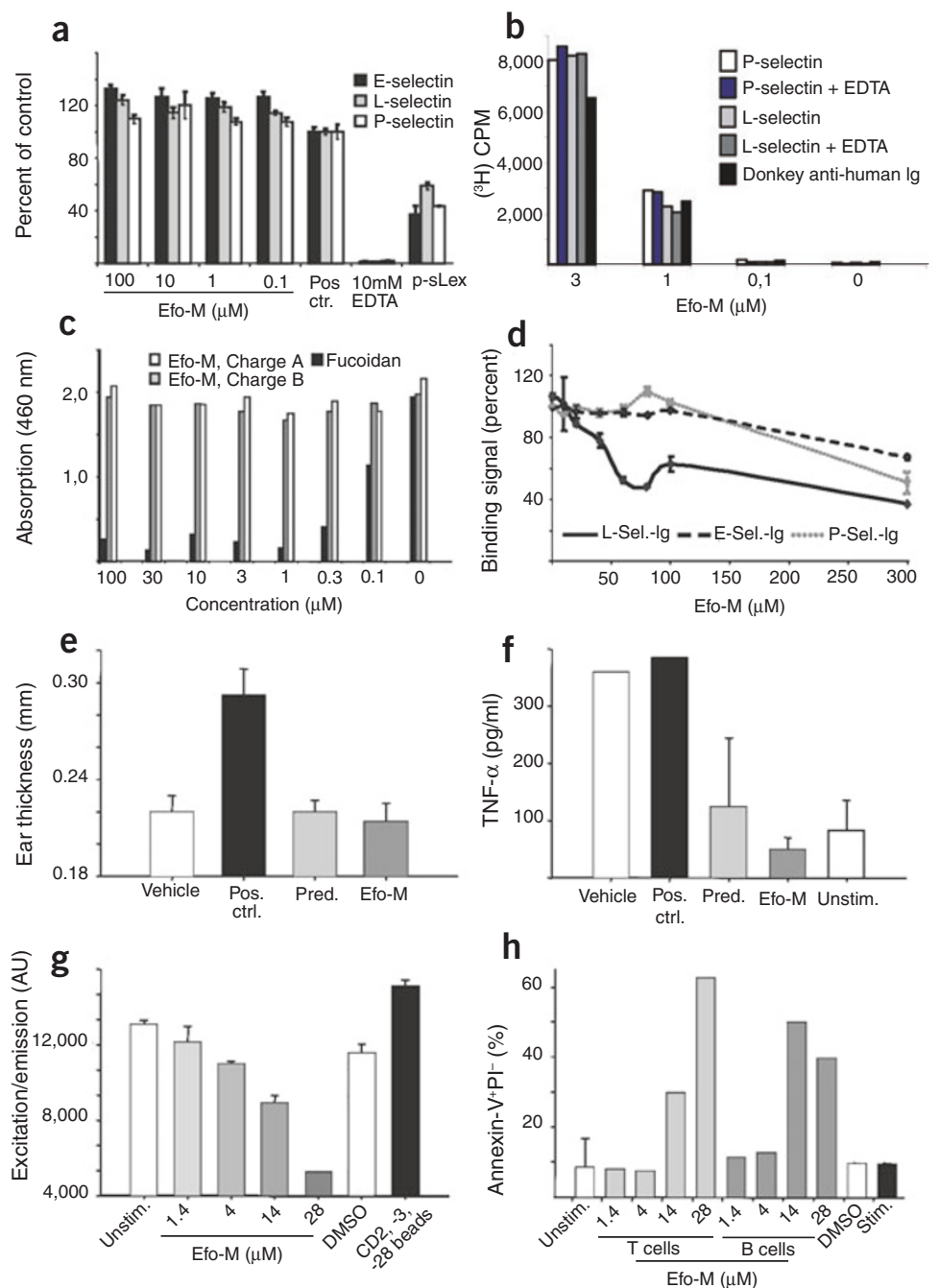
${ }^{*} P<0.05$ (treatment versus DNFB challenge). Prednisolone served as a positive control for anti-inflammatory treatment. Serum levels of Efo-M after systemic administration are shown in Supplementary Figure 9. (f-h) Efo-M interferes with lymphocyte viability/activation. (f) Spleen cells from mice (in e) were stimulated ex vivo with LPS ( $100 \mathrm{ng} / \mathrm{ml}$ for $18 \mathrm{~h}$ or left unstimulated (Unstim.). TNF- $\alpha$ in the supernatants was determined with specific ELISA (triplicate values). (g) Human PBMCs were activated with CD2-, CD3-, CD28-coated beads for $24 \mathrm{~h}$ in the absence or presence of Efo-M. Cell viability and proliferation was assessed ( $y$-axis, 530/590 nm arbitrary units (AU), triplicate values) with AlarmarBlue. Unstimulated, stimulated and cells incubated with the same concentration of the Efo-M solvent DMSO (0.3\%) served as controls. (h) Purified, unstimulated and stimulated human B (LPS, $100 \mathrm{ng} / \mathrm{ml}$ ) and T cells (CD2-, CD3-, CD28-coated beads) were incubated with titrated amounts of Efo-M in 96-well plates. After $18 \mathrm{~h}$, T cells were stained with propidium iodide (PI) and Annexin-V and analyzed in a FACScalibur. For DMSO, stimulated and unstimulated samples, the mean value of B and T cells is given. Results were reproduced in at least two independent experiments. 